\title{
Impairment of facial recognition in patients with right cerebral infarcts quantified by computer aided "morphing"
}

\author{
A Rösler, S Lanquillon, O Dippel, H J Braune
}

\section{Department of \\ Neurology \\ A Rösler \\ H J Braune \\ Department of \\ Psychiatry \\ $S$ Lanquillon}

Institute of Computer Science, Philipps

University, Marburg,

Germany

O Dippel

Correspondence to:

Dr Alexander Rösler,

University Hospital

University Hospital

Marburg, Rudolf-Bultman

Strasse 8, 35033 Marburg,
Germany.

Received 4 March 1996

and in revised form

19 September 1996

Accepted 30 October 1996

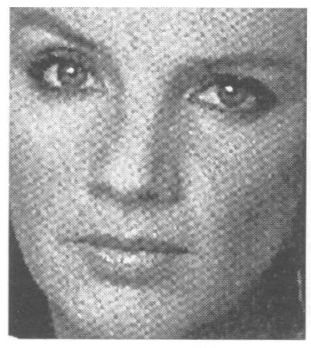

Starting frame
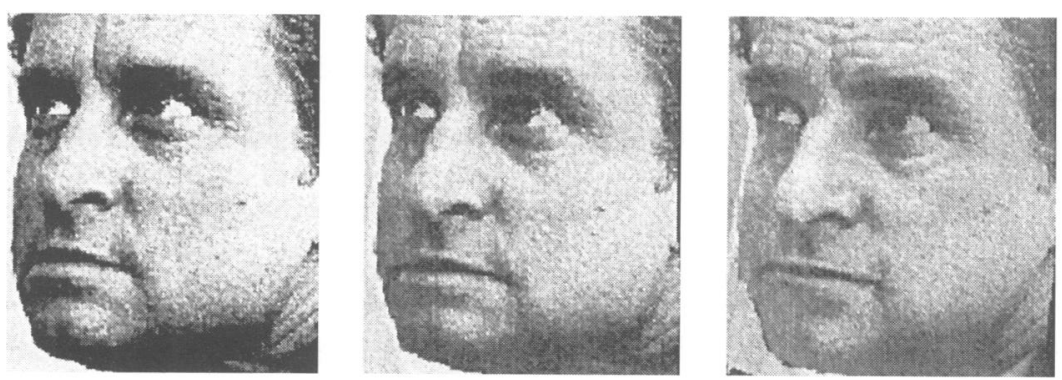

It is unlikely that we are able to distinguish any other object to such a degree as we can human faces. The idea that recognition of a human face could be a function which is independent of other recognition modalities of the brain, and therefore could also be independently disturbed, was finally established by Bodamer in 1947.' Previous to this reports of disturbances in facial recognition had been made by Willebrand ${ }^{2}$ and Charcot. $^{3}$ If we assume an isolated function of facial recognition, two substantial issues arise: (1) Where is it located anatomically? (2) Is there a graded transition from unimpaired recognition of faces to complete prosopagnosia?

\section{Patients and methods}

To elucidate these questions, 31 right handed patients with ischaemic infarcts in the supply area of the middle cerebral artery (15 left sided and 16 right sided infarcts) were studied and compared with 21 age and sex matched controls. The distribution of Barthel indices was the same for left and right sided infarcts (mean $=84$ and median $=90$ for left and mean $=$ 84 and median $=95$ for right sided infarcts). The following inclusion criteria were applied : cranial CT confirmed a single infarction in the supply area of the middle cerebral artery (table 1 shows the topographical distribution); no
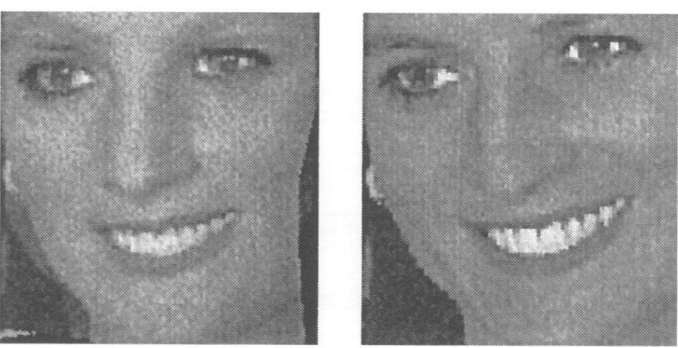

Target photograph
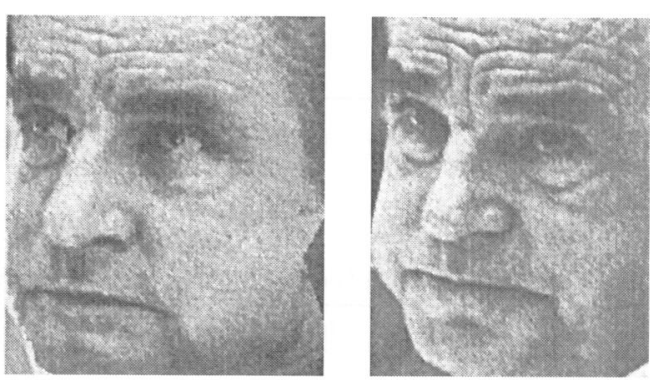

Target photograph

Figure 1 Selection of frames illustrating the morphing process. 
Table 1 Distribution of infarcts by $C T$

\begin{tabular}{lll}
\hline Region & Right infarcts & Left infarcts \\
\hline Cortical: & & \\
Temporo-occipital & 4 & 3 \\
Temporoparieto-occipital & 5 & 4 \\
$\quad$ Frontotemporoparietal & 1 & 2 \\
Subcortical: & 4 & 3 \\
$\quad$ Thalamus and internal capsule & 2 & 3 \\
Basal ganglia & & \\
\hline
\end{tabular}

Table 2 Results with frame Diana

\begin{tabular}{|c|c|c|c|}
\hline & \multicolumn{3}{|l|}{ Attempts } \\
\hline & $\leqslant 25$ & $26-30$ & Failed \\
\hline $\begin{array}{l}\text { Controls }{ }^{\star \star} \\
\text { Left infarcts } \\
\text { Right infarcts }\end{array}$ & $\begin{array}{c}16(76 \cdot 2) \\
6(40) \\
3(18 \cdot 8)\end{array}$ & $\begin{array}{l}2(9 \cdot 5) \\
4(26 \cdot 7) \\
6(37 \cdot 5)\end{array}$ & $\begin{array}{l}3(14 \cdot 3) \\
5(33 \cdot 3) \\
7(43 \cdot 8)\end{array}$ \\
\hline
\end{tabular}

Percentages are in parentheses.

$\star \star P=0.002$.

Table 3 Results with frame Kohl

\begin{tabular}{|c|c|c|c|}
\hline & \multicolumn{3}{|l|}{ Attempts } \\
\hline & $\leqslant 24$ & $25-30$ & Failed \\
\hline $\begin{array}{l}\text { Controls }{ }^{\star \star} \\
\text { Left infarcts } \dagger \\
\text { Right infarcts }\end{array}$ & $\begin{array}{c}16(76 \cdot 2) \\
9(60) \\
5(31 \cdot 2)\end{array}$ & $\begin{array}{l}5(23 \cdot 8) \\
6(40) \\
7(43 \cdot 8)\end{array}$ & $\begin{array}{l}0(0) \\
0(0) \\
4(25)\end{array}$ \\
\hline
\end{tabular}

Percentages are in parentheses.

$\dagger P=0.034 ;{ }^{\star} \mathrm{P}=0.004$.

Table 4 Effect of cortical and subcortical lesions on results with frame Diana

\begin{tabular}{llll}
\hline & Attempts & Failed \\
\cline { 2 - 4 } & $\leqslant 25$ & $26-30$ & \\
\hline Cortical: & 3 & 2 & 4 \\
$\quad$ Left infarcts & 0 & 5 & 5 \\
Right infarcts & 0 & 2 & 1 \\
Subcortical: & 3 & 1 & 2 \\
$\quad$ Left infarcts & 3 & &
\end{tabular}

Table 5 Effect of cortical and subcortical lesions on results with frame Kohl

\begin{tabular}{|c|c|c|c|}
\hline & \multicolumn{3}{|c|}{ Attempts } \\
\hline & $\leqslant 24$ & $25-30$ & Failed \\
\hline \multicolumn{4}{|l|}{ Cortical: } \\
\hline Left infarcts $\star \star$ & 5 & 4 & 0 \\
\hline Right infarcts ${ }^{\star \star}$ & 0 & 6 & 4 \\
\hline \multicolumn{4}{|l|}{ Subcortical: } \\
\hline Left infarcts & 4 & 2 & 0 \\
\hline Right infarcts & 5 & 1 & 0 \\
\hline
\end{tabular}

Table 6 Effect of cortical brain region involved in right sided infarcts with frame Diana

\begin{tabular}{llll}
\hline & Attempts & & \\
\cline { 2 - 4 } & $\leqslant 25$ & $26-30$ & Failed \\
\hline Temporoparieto-occipital & 0 & 1 & 4 \\
Temporo-occipital & 0 & 3 & 1 \\
\hline
\end{tabular}

Table 7 Effect of cortical brain region involved in right sided infarcts with frame Kohl

\begin{tabular}{llll}
\hline & Attempts & \\
\cline { 2 - 4 } & $\leqslant 24$ & $25-30$ & Failed \\
\hline Temporoparieto-occipital & 0 & 1 & 4 \\
Temporo-occipital & 0 & 4 & 0 \\
\hline
\end{tabular}

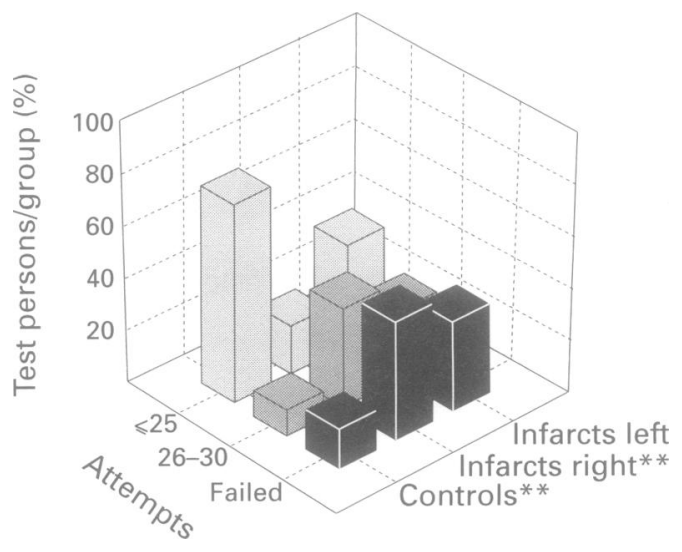

Figure 2 Group comparisons of attempts to identify Diana.

previous or multiple infarcts; tests were done in the second week after the stroke; exclusion of patients with moderate or severe dementia by mini mental status examination ${ }^{4}$; and exclusion of patients with receptive aphasia by the Aachener aphasia test. ${ }^{5}$

Each patient was shown two series of 30 pictures on a video screen (fig 1). In the first series a photo of Jil Sander turned into a portrait of Lady Diana; in the second Michael Douglas was transformed into Helmut Kohl. Patients were given 30 seconds with each frame to recognise Lady Diana and Helmut Kohl. The number of frames needed to identify the target either by name or social function was counted. Characteristics which could have aided in the recognition of the prominent person-for example, hair, glasses, or a tie-were not shown in the photo.

Based on the results of the controls for both series of pictures, categories were developed for normal, late, and non-identification. Seventy five per cent of the controls recognised Diana within 25 and Kohl within 24 attempts; therefore these numbers were set as arbitrary upper boundaries for "normal" recognition. More attempts up to the end point of 30 were considered "late" and no identification at all as "failed". Patients or controls who did not know the target persons even after being told their names, were excluded from analysis. Results were analysed by maximum likelihood $\chi^{2}$ tests. $^{67}$

\section{Results}

Healthy controls recognised Helmut Kohl early in 16 out of 21 cases and late in the remaining five. Diana was recognised early in 16 , late in two, and not at all in three cases.

Patients with left sided infarcts recognised Diana and Kohl later than controls but this was not significant $(P=0.086$ for Diana; $P=$ 0.58 for Kohl).

Patients with right sided infarcts identified Diana and Kohl significantly later than the controls $(P=0.002$ for Diana and $P=0.004$ for Kohl). 
Figure 3 Group comparisons of attempts to identify Kohl.

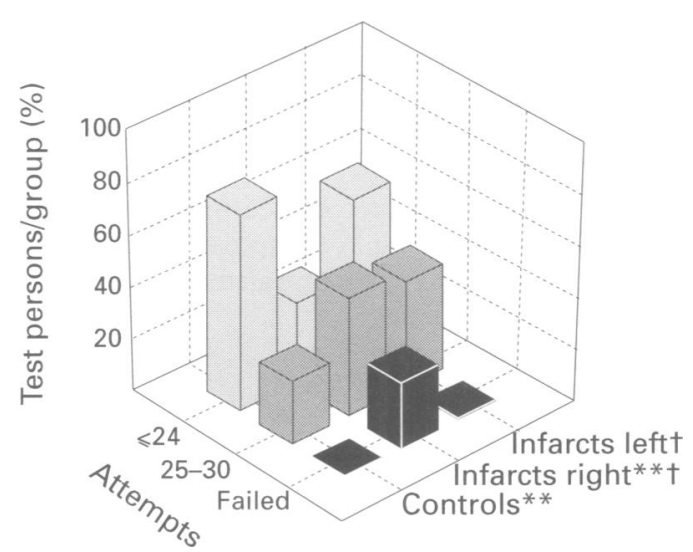

Group comparisons between left and right sided infarcts for Diana did not differ significantly $(P=0.42)$, whereas patients with right sided infarcts identified Kohl significantly later than those with left sided infarcts $(P=0.034)$ (tables 2 and 3, figs 2 and 3).

Subanalysis of cortical involvement by CT showed significant impairment of facial recognition in patients with right sided infarcts for Kohl ( $P=0.001)$ and did not reach significance for Diana $(P=0.06)$, whereas isolated subcortical lesions did not have a significant effect on the recognition task (tables 4 and 5).

Involvement of the parietal lobe in right sided lesions was associated with more recognition failures compared with temporo-occipital lesions alone (tables 6 and 7). No statistical analysis was carried out because of the few patients in these subgroups.

\section{Discussion}

Our patients with right sided infarcts seemed to have more difficulties in identifiying familiar faces than healthy controls and patients with left sided infarctions.

The neuroanatomical localisation of facial recognition and its disturbances still remain controversial. Kolb and Wishaw postulated that the damage which leads to prosopagnosia must be bilateral. Brodman's areas 18 and 19, and additionally 20,21 , and 37 seem to play a part in facial recognition. ${ }^{8}$ Kandel too argued that "lesions that cause prosopagnosia are always bilateral". ${ }^{9}$ In a comprehensive article by Meadows ${ }^{10}$ there were seven postmortem results available from patients who had had prosopagnosia. Five of these had bilateral occipitotemporal lesions, mostly symmetric, in accordance with the study by Damasio et al. ${ }^{11}$ The two other patients had right sided occipitotemporal lesions.

Young et al reported a 51 year old woman who showed a deficit in recognising faces and matching photographs of facial emotional expression after bilateral partial amygdalotomy. ${ }^{12}$

On the other hand there is little doubt that the right hemisphere plays an important part in facial recognition: Hecaen and Angeluerges made a list of neurological signs which were positively associated with prosopagnosia. ${ }^{13}$
The disorder showed associated signs such as left visual field defects in $91 \%$ of the cases, disturbances of spatial orientation, constructive apraxia, and neglect. This enumeration alone indicates that right sided lesions are obviously more often related to impaired facial recognition. The high number of combinations with left upper quadrantanopia led to the assumption that the underlying lesion could be in the right basal occipital lobe. Miller described delayed recognition of faces in patients who had undergone right temporal lobectomy. ${ }^{14}$ In a more recent article, Evans et al reported the case of a 68 year old woman with progressive atrophy of the right temporal lobe developing progressive prosopagnosia. ${ }^{15}$ In a recent review Boeri and Salmaggi favoured a right posterior lesion in what they called true prosopagnosia, ${ }^{16}$ and a patient reported by Sergent and Poncet had a large right parietotemporal lesion sparing the medial posterior temporal cortex. ${ }^{17}$

These in part contradictory results suggest the possibility of different forms of impaired facial recognition.

Thus Bruce and Young developed a functional model of face processing which divides facial processing into different modalities. After a basic process of structural encoding, there should be different pathways to the analysis of facial expression, the recognition of familiar faces, and the matching of unfamiliar faces. ${ }^{18}$

We know that object recognition is processed by a ventral pathway constituted by occipito-temporal cortices. On the other hand, visuospatial processing of the visual scene is comprised of parieto-occipital pathways. Different modalities for the recognition of faces play a synergistic part. When healthy persons have to discriminate elementary features like colour, the prestriate cortex and in particular the fusiform gyrus is activated. Perceptual integration takes place in the posterior part of the lingual gyrus and, in a third step, especially important for the recognition of faces, mainly the anterior part of the lingual gyrus and the parahippocampic gyrus are activated in attributing meaning to the "percept". ${ }^{19}$

Despite this well established topographical association between the visual recognition process and the brain region involved, there is still no consensus on the question of lateralisation of different facial recognition modalities. For instance, results of analysing emotional facial expression are controversial:

Young et al examined 32 servicemen 40 years after they had sustained a penetrating missile injury to the brain in the second world war and found that expression analysis was selectively impaired in five patients with left hemispheric lesions, ${ }^{20}$ although earlier this task had mainly been thought to be located in the right hemisphere..$^{21} 22$

Superiority of the right hemisphere was also claimed for the function of visual attention according to Dimmond and Heilmann. ${ }^{2324}$ It could therefore be argued that the impairment of facial recognition in our patients with right 
sided lesions might be partly due to failure of arousing visual interest in the emotional expression of the face shown. However, the lateralisation of visual attention remains controversial: Posner showed that patients with left or right parietal lesions were equally impaired in directing their attention to stimuli in both visual fields. ${ }^{25}$

The studies mentioned were all carried out on patients with relatively longstanding brain defects, whereas in our patients the interval of one week between the event of infarction and the morphing task was presumably too short to allow selective testing for single modalities of facial recognition. This view is supported by the well known finding in other neuropsychological syndromes-for example, aphasia or apraxia - that a final distinction of different subforms is not usually possible in the acute phase of brain damage.

In general we may state that the complex function of facial recognition requires the integrity of the right temporoparieto-occipital region. This anatomical region was damaged to different extents in our patients. Three of five patients with right temporoparieto-occipital lesions failed to recognise both target pictures, the remaining two of this group received lower scores (28 for Diana and "failed" for Kohl, 28 for Kohl and "failed" for Diana) than the group of patients with temporo-occipital involvement, in which only one of four patients failed with Diana and all four recognised Kohl. Despite the small case numbers in these subgroups, these results suggest a possible key role for the parietal region in facial recognition.

In accordance with the results of Young and Tupler, ${ }^{20}{ }^{26}$ our patients with lesions involving cortical regions were significantly impaired in our test of facial recognition, whereas the six patients with subcortical lesions only were not (tables 2 and 3).

Our patients, like others with right hemisphere damage, did not complain about difficulties recognising faces. Probably these deficits are easy to compensate for, because recognising a certain person "behind" a face in daily life is made easy by the perception of further visual and acoustic cues. ${ }^{27}$

Among the tested patients with right sided cortical infarctions there were none with prosopagnosia in a "pure" sense, although there was a clear impairment in recognition of familiar faces; graded disturbances in the sense of a "prosophypognosia" in this common neurological disease do seem to exist.

With the exception of the Benton-Van Allen facial recognition test there are only experimental tests available for the function of facial recognition. ${ }^{28}$
As Puschel and Zaidel showed, the BentonVan Allen test is not able to discriminate between patients with damage in the left or right hemisphere. ${ }^{29}$

Morphing programs with a variable number of features are widely available for personal computers and enable sensitive testing for impairment of facial recognition.

1 Bodamer J. Die Prosop-agnosie. Arch Psychiatr Nervenkrankheiten 1947;179:6-53.

2 Willebrand H. Ein Fall von Seelenblindheit und Hemianopsie mit Sectionsbefund. Deutsch Z Nervenheilk 1892 2:361-5.

3 Charcot JM. Un cas de suppression brusque et isolee de la vision mentale des signes et des objets (formes et couleurs ). Progr Med 1883;11:568-74.

4 Folstein MF, Folstein SE, Hugh PR. "Mini-mental-state". A practical method for grading the cognitive state of practical method for grading the cognitive state of
patients for the clinician. $\mathcal{F}$ Psychiatr Res 1975;12:189-98.

patients for the clinician. F Psychiatr Res 1975;12:189-98.
5 Huber W, Poeck K, Weniger D, Willmes K. Der Aachener Aphasie Test. Güttingen: Holzgrefe, 1983.

6 Bishop YMM, Fienberg SE, Holland PW. Discrete multivariate analysis. Cambridge, MA: MIT Press, 1975

7 Fienberg SE. The analysis of cross-classified categorical data Cambridge, MA: MIT Press, 1977

8 Kolb B, Wishaw IQ. Fundamentals of human neuropsychol ogy. New York: W H Freeman, 1990, 236-7.

9 Kandel ER, Schwartz JT, Jessel TM. Principles of neurosciences. New York: Elsevier, 1991, 458-9.

10 Meadows JC. The anatomical basis of prosopagnosia. Neurol Neurosurg Psychiatry 1974;37:489-501.

11 Damasio AR, Damasio H, Van Hoesen GW. Prosopagnosia: anatomic basis and behavioural mechanisms. Neurology 1982;32:33-41.

12 Young AW, Aggleton JP, Hellawell DJ, Johnson M, Brooks Young AW, Aggleton JP, Hellawell DJ, Johnson M, Brooks P, Hanley JR. Face processing im

13 Hecaen H, Angelergues R. Agnosia for faces (prosopagnosia). Arch Neurol 1972;7:92-100

14 Miller B. Visual recognition and recall after right temporal lobe excision in man. Neuropsychologia 1968;6:191-209.

15 Evans JJ, Heggs AJ, Antoun N, Hodges JR: Progressive prosopagnosia associated with selective right temporal lobe atrophy-a new syndrome? Brain 1995;118:1-13

16 Boeri R, Salmaggi A. Prosopagnosia. Current Opinion in Neurology 1994;7:61-4.

17 Sergent J, Poncet M. From covert to overt recognition of faces in a prosopagnosic patient. Brain 1990;113: 989-1004.

18 Bruce V, Young A. Understanding face recognition. $\mathrm{Br} \mathcal{F}$ Psychol 1986;77:305-27.

19 Ceccaldi M. Visual object agnosia. Handout, teaching course Neuropsychology. First Congress of the European Federation of Neurological Societies Marseille: France, Federation

20 Young AW, Newcombe F, de Haan EHF, Small M, Hay DC. Face perception after brain injury. Brain 1993;116: $941-59$

21 Etcoff NL. Selective attention to facial identity and facial emotion. Neuropsychologia 1984;22:281-95.

22 Suberi M, McKeever WF. Differential right hemisphere memory storage of emotional and non-emotional faces. Neuropsychologia 1977;15:757-68.

23 Dimmond SJ, Beaumont JG. Differences in vigilance performance of the right and left hemisphere. Cortex 1973, 9:259-65.

24 Heilman KM, van den Abell T. Right hemisphere dominance for mediating cerebral activation. Neuropsychologia 1979;17:315-21.

25 Posner MI, Walker JA, Friedrich JJ, Rafal RD. Effects of parietal lobe injury on covered orienting of visual attenparietal lobe injury on covered o
tion. $\mp$ Neurosci $1984 ; 4: 1863-74$.

26 Tupler LA, Coffey CE, Logue PE, Djang WT, Fangan SM. Neuropsychological importance of subcortical white SM. Neuropsychological importance of subcortical wh
matter hyperintensity. Arch Neurol 1992;49:1248-52.

27 Von Cramon D, Mai N, Ziegler W, eds. Neuropsychologische Diagnostik. London: Chapman and Hall, 1995, 29-33.

28 Benton AL, Hamsher $\mathrm{K}$ de S, Varney N, Spreen $O$ Contributions to Neuropsychological assessment: a clinical manual. Oxford: Oxford University Press, 1983.

29 Puschel J, Zaidel E. The Benton-van Allen faces: a lateralized tachistoscopic study. Neuropsychologia 1994;32 357-67. 